\title{
Integrating Continuing Education Credits to a Collegiate EMS Training Model
}

\author{
David Gordon, EMT; Maya Ganeshan, EMT; Eugene Janda, MES, CFPS, NFPA; Laura Farrington
}

POSTER PRESENTATION ABSTRACT | PROGRAM DEVELOPMENT \& EVALUATION CATEGORY

Introduction: Ongoing continuing medical education (CME) is an important consideration for collegiate EMS programs because an EMT may need to recertify (every 2 or 3 years) during their collegiate EMS tenure. At the same time, the frequent turnover of training leadership roles may prevent students from being state-certified EMS instructors. In Pennsylvania, providers need 24 pre-approved online or in-person CME hours to recertify, which providers may complete independently from agency-specific training.

Program Development \& Implementation: The University of Pennsylvania Medical Emergency Response Team (MERT) develops 1015 student-led training drills per academic semester, which each EMT attends. Those unable to attend are required to complete Pennsylvania-CME online to make up the missed training. MERT sought a solution that positively encouraged EMTs to attend agency-specific training while providing CME in a matter logistically feasible for collegiate EMS agencies. For training drills, MERT recruited paramedics from Public Safety and physicians from the University Health System to assist in planning and mentoring students on a range of EMS topics. MERT leveraged a close partnership with the Division of Public Safety's Fire and Emergency Services (FES) and their regional-EMS teaching certificate agency to actuate the CME training sessions. Following drills, the training coordinator works closely with FES to submit CME credit approval paperwork to regional-EMS.

Program Evaluation: In October 2018, MERT piloted the CMEs and organized a symposium with 6 guest speakers attended by 50 providers from 4 collegiate EMS agencies. With plans to integrate at least $8 \mathrm{CME}$ credits into MERT's training semester curriculum, providers who attended each required training will complete all credits necessary to recertify. So far, most providers elected to enroll in the CMEs.

Discussion/Conclusions: Other collegiate EMS agencies may potentially be able to utilize teaching certificates from their hospitals and public safety to adapt their training programs for members to ensure compliance with the CME licensing requirements.

Author Affiliations: From Medical Emergency Response Team, University of Pennsylvania, Philadelphia, PA, USA (D.G., M.Y.); Fire and Emergency Services, Division of Public Safety, University of Pennsylvania, Philadelphia, PA, USA (E.J., L.F.).

Address for Correspondence: David Gordon, EMT.

Email: davgor@sas.upenn.edu

Conflicts of Interest/Funding Sources: By the JCEMS Submission Declaration Form, all authors are required to disclose all potential conflicts of interest and funding sources. The authors declared that they received funding from the University of Pennsylvania Division of Public Safety, University of Pennsylvania Division of the Vice Provost for University Life, and University of Pennsylvania Robert A. Fox Leadership Program for the program and/or research described in this abstract.

Ethical Compliance: The authors attest that the research associated with this abstract was conducted in accordance with the JCEMS Ethics Guidelines.

Submission History: Received January 6, 2019; accepted for presentation and publication February 11, 2019.

Poster Presentation: This abstract was presented as a poster at the Academic Poster Session of the $26^{\text {th }}$ Annual Conference of the National Collegiate Emergency Medical Services Foundation; February 23, 2019; Pittsburgh, PA, USA.

Published Online: December 31, 2019

Published in Print: December 31, 2019 (Volume 2: Supplemental 1)
Reviewer Information: In accordance with JCEMS editorial policy, poster presentation abstracts undergo double-blind peer-review by at least two reviewers (JCEMS Editorial Board members and/or independent reviewers) prior to acceptance for presentation and publication. JCEMS thanks the anonymous reviewers who contributed to the review of this work.

Copyright: (C) 2019 Gordon, Ganeshan, Janda \& Farrington. This is an open access abstract distributed under the terms of the Creative Commons Attribution $4.0 \mathrm{In}$ ternational (CC BY 4.0) License, which permits unrestricted use, distribution, and reproduction in any medium, provided the original author and source are credited. The full license is available at: https://creativecommons.org/licenses/by/4.0/ Electronic Link: https://doi.org/10.30542/JCEMS.2019.02.S1.07 